\title{
Agricultura Familiar e Soluções Tecnológicas - agentes locais como protagonistas na geração de conhecimento
}

\author{
Alex Alexandre Mengel \\ Universidade Federal do Rio Grande do Sul - Tramandaí - RS - Brasil \\ ORCID: https://orcid.org/0000-0002-5470-4922 \\ Silvia Lima de Aquino \\ Universidade Federal do Rio Grande do Sul - Tramandaí - RS - Brasil \\ ORCID: https://orcid.org/0000-0002-7782-4345 \\ Cidonea Machado Deponti \\ Universidade de Santa Cruz do Sul - Santa Cruz do Sul - RS - Brasil \\ ORCID: http://orcid.org/0000-0001-8833-1450 \\ Silvio Cezar Arend \\ Universidade de Santa Cruz do Sul - Santa Cruz do Sul - RS - Brasil \\ ORCID: https://orcid.org/0000-0001-7685-3710
}

\begin{abstract}
Resumo
O presente trabalho é parte dos resultados do projeto de pesquisa em andamento intitulado "Análise do papel dos agricultores familiares na geração de soluções tecnológicas para a agricultura". Objetiva: 1) compreender o papel dos agricultores familiares como agentes relevantes na geração de conhecimentos materializados em novos processos, produtos, técnicas e tecnologias para a agricultura; 2) identificar quais os caminhos conduzem à produção desses conhecimentos e quais suas possíveis potencialidades de transformação neles contidos. Para a localização das soluções geradas pelos agricultores criou-se uma rede de colaboradores que aplicaram um formulário - construído em parceria entre os agentes nos anos 2017 e 2018. Posteriormente, organizou-se e sistematizou-se os dados coletados. Os colaboradores (equipe do projeto composta por professores, pesquisadores, bolsistas e acadêmicos) localizaram 58 técnicas, tecnologias, processos ou produtos gerados por agricultores familiares. A partir das soluções encontradas, a equipe de pesquisa realizou 18 entrevistas semiestruturadas com os agentes responsáveis pela criação de novos processos, técnicas e equipamentos para a agricultura familiar. Concluiu-se que a geração de soluções tecnológicas próprias é um elemento característico e definidor dos agricultores familiares como categoria, tendo em vista que estabelecem e têm clareza sobre os objetivos de sua atividade socioeconômica, ao mesmo tempo em que desenvolvem cada uma das tarefas existentes em sua unidade produtiva. Tal característica permite que o agricultor familiar identifique os problemas de cada processo e pense maneiras de solucioná-lo, seja modificando um método produtivo ou criando uma nova máquina ou equipamento.

Palavras-chave: Resiliência. Identidade. Agência. Conhecimento. Tecnologia agrícola.
\end{abstract}




\section{Family Farming and Technology Solutions - local agents as protagonists in knowledge generation}

\section{Abstract}

This paper is part of the results of the ongoing research project entitled "Analysis of the role of family farmers in generating technological solutions for agriculture". Objective: 1) to understand the role of family farmers as relevant agents in the generation of materialized knowledge in new processes, products, techniques and technologies for agriculture; 2) identify which paths lead to the production of this knowledge and what their transformation potentials. For the localization of the solutions generated by the farmers, a network of collaborators was created who applied a form - built in partnership between the agents - in 2017 and 2018. Subsequently, the collected data was organized and systematized. The contributors (project team of teachers, researchers, and students) located 58 techniques, technologies, processes, or products generated by family farmers. From the solutions found, a research team conducted 18 semi-structured interviews with agents responsible for creating new processes, techniques or equipment for family farming. It was concluded that the generation of own technological solutions is a characteristic and defining element of family farmers as a category, considering that they establish and have clarity about the objectives of their socioeconomic activity, while developing each of the existing tasks in your productive unit. This feature allows the family farmer to identify the problems of each process and think of ways to solve it, either by modifying a production method or by creating a new machine or equipment.

Keywords: Resilience. Identity. Agency. Knowledge. Agricultural technology.

\section{Agricultura Familiar y Soluciones Tecnológicas - agentes locales como protagonistas en la generación de conocimiento}

\section{Resumen}

Este trabajo forma parte de los resultados del proyecto de investigación en curso titulado "Análisis del papel de los agricultores familiares en la generación de soluciones tecnológicas para la agricultura". Objetivo: 1) comprender el papel de los agricultores familiares como agentes relevantes en la generación de conocimiento materializado en nuevos procesos, productos, técnicas y tecnologías para la agricultura; 2) identificar cuáles son los caminos que conducen a la producción de este conocimiento y cuáles son sus posibles potenciales de procesamiento. Para localizar las soluciones generadas por los agricultores, se creó una red de colaboradores, que aplicó una forma -construida en asociación entre los agentes- en los años 2017 y 2018. Posteriormente, se organizaron y sistematizaron los datos recogidos. Los colaboradores (equipo del proyecto compuesto por profesores, investigadores, becarios y académicos) localizaron 58 técnicas, tecnologías, procesos o productos generados por los agricultores familiares. Con base en las soluciones encontradas, el equipo de investigación realizó 18 entrevistas semiestructuradas con los agentes responsables de la creación de nuevos procesos, técnicas y equipos para la agricultura familiar. Se concluyó que la generación de soluciones tecnológicas propias es un elemento característico y definitorio de los agricultores familiares como categoría, ya que establecen y tienen claridad sobre los objetivos de su actividad socioeconómica, a la vez que desarrollan cada una de las tareas existentes en su unidad productiva. Esta característica permite al agricultor familiar identificar los problemas de cada proceso y pensar en formas de resolverlos, ya sea modificando un método de producción o creando una nueva máquina o equipo.

Palabras clave: Resistencia. Identidad. Agencia. Conocimiento. Tecnología agrícola. 


\section{Introdução}

O presente artigo tem como objetivo compreender o papel dos agricultores familiares como agentes relevantes na geração de novos processos, produtos, técnicas e tecnologias para a agricultura'. Para tanto, procura identificar que caminhos conduzem à produção desses conhecimentos e quais as potencialidades de transformação que ensejam.

O uso do termo agente justifica-se pela relação estabelecida com o conceito de agência, esta é a capacidade de interferir em eventos, não necessariamente de modo intencional. Agir, mais do que pretender algo, é ser significativo na sua ocorrência, na medida em que a "ação depende da capacidade do indivíduo de 'fazer uma diferença' em um estado pré-existente de coisas ou curso de eventos" (GIDDENS, 1984, p. 14). Um agente deixa de o ser quando perde a capacidade para "criar uma diferença", isto é, de exercer alguma espécie de poder (GIDDENS, 2009, p. 17).

Long (2007) ainda salienta que a habilidade de influenciar a ação dos outros depende, fundamentalmente, da existência ou da criação de redes de relações com atores relevantes ou com atores que podem mobilizar e envolver colaboradores em alguma tentativa de alcançar fins comuns ou pelo menos compatíveis.

Nestes termos, o trabalho procura problematizar a visão que toma os agricultores apenas como sujeitos incumbidos da produção de artigos agropecuários. Entende-se que os conhecimentos produzidos por estes sujeitos, em geral, pouco considerados pelos trabalhos acadêmicos que tem como objeto o mundo rural, bem como aqueles que se debruçam sobre a produção de conhecimentos para a sociedade: 1) fazem parte da construção de suas identidades, sendo então, um elemento que os caracterizam; 2) contribuem para a reprodução social do segmento; 3) e, portanto, são capazes de colaborar com a manutenção e em especial, com a renovação da agricultura familiar. Logo, evidenciam a resiliência da agricultura da familiar, já que esta é capaz de suscitar rearranjos institucionais e produtivos extremamente criativos, que a leva a obter ganhos de escala, o que pode proporcionar também que este segmento reafirme seu importante papel na construção de novos modelos de desenvolvimento rural (BAIARDI e ALENCAR, 2014).

Na literatura, autores como Wanderley (1999), Jean (1994), Schneider (2003, Abramovay (1998) refletem sobre a temática da agricultura familiar e o papel dos agricultores como protagonistas do próprio devir. Wanderley (1999) defende que o agricultor familiar brasileiro não é um personagem passivo, pois, ao longo da história, tem buscado com suas forças traçar estratégias para lutar por seu espaço, adaptando-se às exigências da agricultura moderna, sem perder características camponesas. Por isso, aliás, afirma a autora que o conceito de camponês é ressemantizado, na medida em que o atual agricultor familiar recorre a sua experiência camponesa, evidenciando a sua capacidade de resistência e de adaptação às transformações mais gerais da sociedade.

1 Este trabalho consiste em parte dos resultados do projeto de pesquisa em andamento intitulado "Análise do papel dos agricultores familiares na geração de soluções tecnológicas para agricultura", financiado pelo CNPq, por meio do Edital Universal 01/2016. Agradecemos a professora Maristela de Paula Andrade pela leitura cuidadosa e pelas valiosas contribuições ao presente artigo. 
Na mesma linha, Schneider destaca que as famílias têm um papel ativo, pois a continuidade de sua reprodução depende de suas decisões e estratégias. "A reprodução social, econômica, cultural e simbólica das formas familiares dependerá de um intricado jogo pelo qual as unidades familiares se relacionam com o ambiente e o espaço em que estão inseridas" (SCHNEIDER, 2003, p. 114).

O protagonismo dos agricultores para seu devir é reconhecido na bibliografia brasileira. Mas como resistem? Esta questão possibilita uma variedade de respostas, pois a ação destes atores é multifacetada. Aqui, observa-se como a geração de novos conhecimentos é um elemento fundamental neste processo, contribuindo para a definição da ação de tais atores como categoria social. Neste sentido, a presente análise trata de como os agricultores familiares, em sua reflexão diária sobre sua inserção socioprodutiva conseguem gerar novas maneiras de se relacionar com a natureza, por meio de seu trabalho.

Como objeto de pesquisa, conseguir captar tal reflexão cotidiana não é tarefa fácil. Desta forma, a maneira mais simples de identificá-la seria a localização de novas ferramentas de trabalho, sejam elas máquinas ou equipamentos, tendo em vista que estas materializam uma reflexão sobre a técnica, como será evidenciado neste artigo por meio de Pinto (2005).

Primeiramente, para a realização do trabalho é essencial explicar a razão de considerar os agricultores familiares uma categoria social que, possivelmente, gera novos e relevantes conhecimentos para a sociedade, expressos em soluções tecnológicas. Soluções tecnológicas aqui são tratadas como novas técnicas ou tecnologias que, ao serem desenvolvidas e inseridas no processo produtivo, modificam a maneira segundo a qual os agricultores se relacionam com a natureza, ou seja, que transformam sua maneira de trabalhar e de viver. Para explicar a razão de considerar os agricultores como geradores de conhecimento e desenvolvedores de tais soluções, utilizam-se as reflexões de Joseph Schumpeter, Maria Nazareth Baudel Wanderley e Álvaro Vieira Pinto.

O presente artigo está dividido em cinco partes, considerando esta introdução e as conclusões. Na segunda seção discute-se os conceitos de conhecimento, tecnologia, técnica, soluções tecnológicas e a razão de considerar os agricultores familiares como protagonistas no processo de geração de conhecimentos próprios, relevantes à sua própria existência. Na terceira seção apresenta-se as ferramentas metodológicas desenvolvidas e utilizadas no trabalho, que permitiram a realização da presente reflexão. Na quarta seção apresenta-se os resultados obtidos e realizase a discussão dos mesmos à luz do referencial teórico e ferramental metodológico utilizado. Por último, apresenta-se as conclusões obtidas após a análise.

\section{Técnica, Tecnologia e produção de conhecimentos: uma reflexão sobre o papel do agricultor nestes processos.}

Álvaro Vieira Pinto, em “O conceito de tecnologia” (2005), explica que há íntima ligação entre o desenvolvimento da técnica e as relações sociais onde ela está inserida. O autor ressalta que a técnica é desenvolvida com um fim produtivo, com vistas a manter ou modificar a posição de seu promotor nas relações sociais nas quais está envolvido, de acordo com os próprios objetivos de seu criador. É a própria técnica "a manifestação da capacidade vital, possuída pelo homem, de produzir o seu 
próprio ser, a qual, por isso, se revela inseparável de todos os atos que pratica" (PINTO, 2005, p. 155).

A técnica, desta maneira, é a expressão da própria humanidade, sendo que somente os seres humanos detêm a capacidade de executar uma atividade, refletir sobre ela, planejar sua mudança e executar as modificações conforme o planejado, para atingir um fim esperado. Assim, todo indivíduo detém, potencialmente, a capacidade de refletir sobre sua ação, bem como modificá-la, desenvolvendo novos métodos, sejam eles por novas técnicas ou tecnologias. Nesta perspectiva, diferentemente dos outros animais, os seres humanos produzem a própria existência, sendo a técnica o meio para esta produção. Desta maneira, ao considerar uma categoria como capaz de gerar e modificar as técnicas que utiliza, entende-se que ela pode produzir ou modificar sua própria relação com a natureza, que ela pode produzir seu lugar histórico como ser humano, que pode definir seu próprio lugar nas relações sociais das quais faz parte e que este lugar não é gerado por outras categorias.

Já a máquina é a expressão do estudo da técnica, está intimamente ligada ao conhecimento de seu construtor. Está ligada a um modo de fazer que ela própria não pode conceber ou modificar, tendo seu desempenho sido fixado anteriormente pelo construtor. "O modo de fazer consiste em uma série ordenada de operações, tendo em vista, de um lado, o fim a alcançar, o produto a fabricar, e, de outro lado, as propriedades da matéria que é obrigada a utilizar e as resistências a vencer" (PINTO, 2005, p. 135).

A máquina é concebida a partir do estudo minucioso da técnica que precisa executar, agora sem a energia dos indivíduos necessários para a realização das tarefas que passam a ser por ela desempenhadas. "Pelo aspecto dinâmico a máquina resume e prefigura uma sucessão de atos que, por levarem ao fim pretendido, explicam a forma a ela atribuída e as funções que deve exercer. A sucessão de atos representa a técnica de produção que tal máquina é capaz de realizar" (PINTO, 2005, p. 135).

De acordo com Pinto (2005), todo ser humano em suas atividades pode refletir sobre suas ações e modificá-las para, com isso, ter resultados mais próximos de seus objetivos. Diante disso, o presente trabalho pretende refletir sobre a seguinte questão: o que torna os agricultores familiares uma categoria especialmente capaz de gerar soluções tecnológicas?

A resposta pode ser encontrada nas reflexões de Schumpeter (1997), quando o autor diferencia trabalho dirigente de trabalho dirigido e trabalho assalariado de trabalho autônomo. O trabalho dirigente é tão importante que o autor o considera como um fator produtivo. Em sua perspectiva o trabalho dirigente é criativo porque, ao realizá-lo, o trabalhador estabelece seus próprios objetivos, ao mesmo tempo em que tem a liberdade para a criação de novos métodos, técnicas, processos, tecnologias, mercados, produtos. Do mesmo modo, "podemos delinear a distinção entre trabalho autônomo e assalariado “[...]. O trabalho autônomo é algo peculiar precisamente na medida em que possui a função de trabalho dirigente, ao passo que de resto não difere em nada do trabalho assalariado" (SCHUMPETER, 1997, p. 37). 
Os agricultores familiares são esses agentes que exploram sua própria mão de obra, mas que, diferentemente dos assalariados, têm a liberdade de modificar os processos produtivos visando atingir os objetivos almejados. Podem refletir sobre todos os processos, pois desempenham cada um deles tendo em mente o objetivo de seu empreendimento. Diferentemente de um trabalhador fabril ou de um trabalhador de uma grande empresa agrícola, que sabe desempenhar somente as atividades para as quais foi contratado, o agricultor familiar tem a visão de cada procedimento a partir do objetivo de sua ação social, qual seja, gerar recursos econômicos para a manutenção de sua família.

Nesse sentido Wanderley (2015) destaca que os agricultores familiares detêm um papel especial, quando comparados com outros trabalhadores. Para a autora, é este lugar que define o "ser" agricultor.

\begin{abstract}
O lugar que assumem no mundo do trabalho constitui o elemento central que forja a sua própria identidade social. Porém, no caso que estamos aqui considerando, não se trata de um trabalho qualquer. $O$ que está fortemente em questão é que tipo de trabalho corresponde à inclusão social desse trabalhador em particular. A maioria dos agricultores antes considerados "periféricos" reivindica o reconhecimento de sua identificação com um tipo de trabalho específico, aquele exercido de forma autônoma, em caráter familiar, através da posse e controle dos meios de produção necessários. Em outras palavras, inclusão social para os próprios produtores significa o reconhecimento de sua condição de agricultor, de suas formas de trabalhar e produzir, cujas potencialidades devem ser apoiadas pelas políticas públicas (WANDERLEY, 2015, p. 39).
\end{abstract}

Para Wanderley (2015), assim como para outros estudiosos do campesinato, tais como Wolf (1972) e Shanin (2005), o trabalho autônomo confere identidade e, portanto, caracteriza o agricultor familiar. Neste sentido, conforme a autora, é necessário explorar as possibilidades geradas por este tipo de trabalho. O presente artigo pressupõe que este tipo de trabalho possibilita a criação de modos específicos de relacionar-se com a natureza, ou seja, possibilita aos agricultores a agência no processo de criação de novas técnicas e tecnologias, o que permite a reprodução social da categoria e define sua existência.

\title{
3 Ferramentas Metodológicas
}

Os dados empíricos utilizados para fundamentar o presente artigo foram apreendidos a partir de trabalho de campo na microrregião que compõe o Conselho Regional de Desenvolvimento (COREDE) do Vale do Rio Pardo, no Rio Grande do Sul. O COREDE Vale do Rio Parto está situado na mesorregião Centro-Oriental do estado e compreende um total de vinte e três municípios (Figura 1). 
Figura 1. Mapa político do COREDE Vale do Rio Pardo

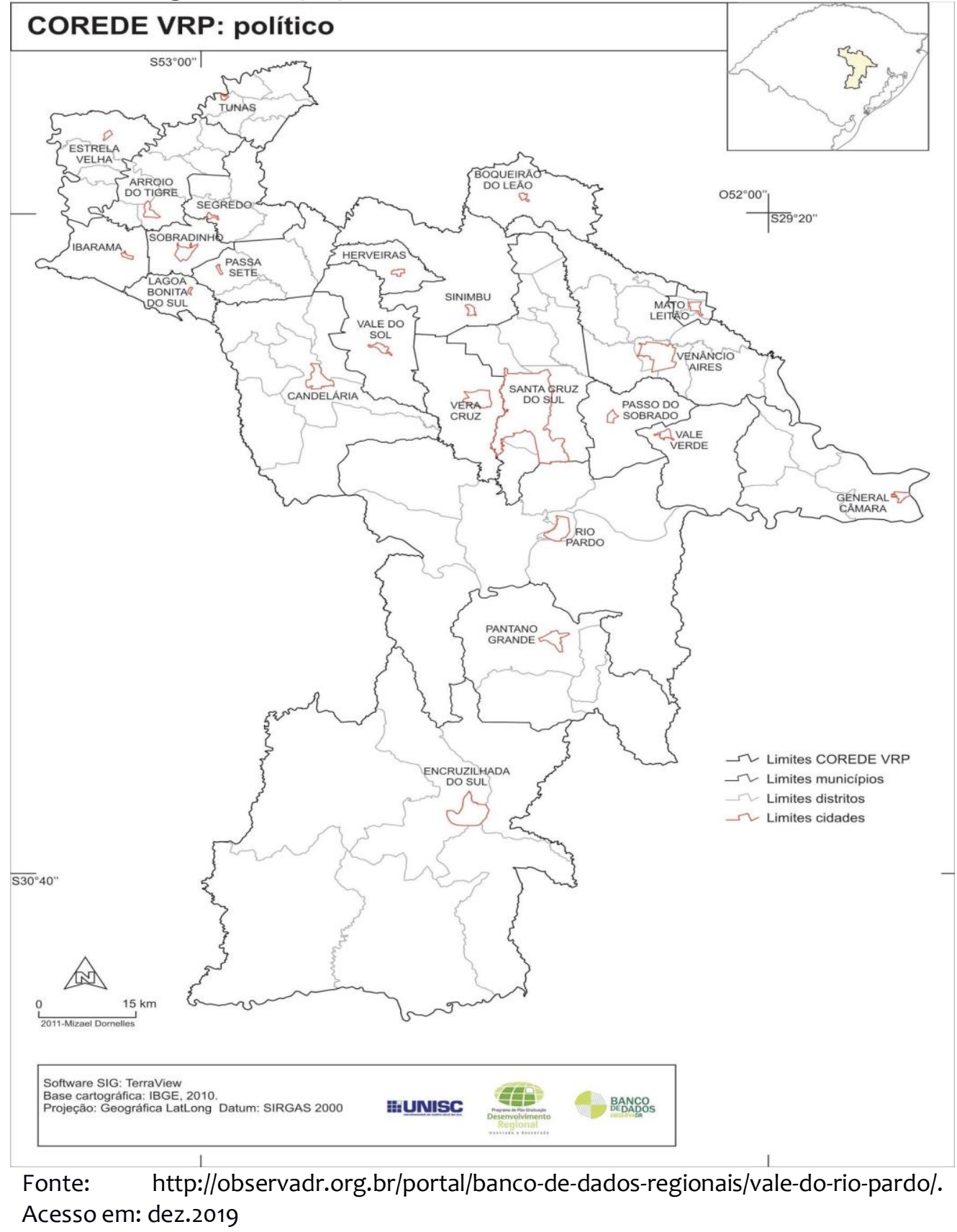

Esta escolha deve-se à importância da agricultura familiar para a região, pois no Rio Grande do Sul os estabelecimentos pertencentes a categoria social agricultura familiar estão concentrados, justamente, nas mesorregiões Noroeste e CentroOriental (FEIX e JUNIOR, 2015). Ademais, de acordo com Karnopp (2012), no Vale do Rio Pardo, aproximadamente, $40 \%$ da população vive e trabalha no campo, em pequenos estabelecimentos familiares, que possuem em média, 18 hectares.

Tendo em vista a dispersão geográfica característica da agricultura familiar por um lado e, por outro, a dificuldade de localizar os agricultores e demais agentes ligados à agricultura que geram novos processos, técnicas e equipamentos para suas atividades, optou-se por um método de pesquisa que tivesse participação direta de agentes locais. Neste sentido, o primeiro passo foi construir uma rede ampla de colaboradores que conhecessem a realidade da agricultura e da agroindústria familiar 
na região e que quisessem participar do projeto, sendo que os interessados foram: a Escola Família Agrícola de Santa Cruz do Sul, a Empresa de Assistência Técnica e Extensão Rural-EMATER/RS, a Associação dos Fumicultores do Brasil e o Arranjo Produtivo Local (APL) Produção de Alimentos e Agroindústria do Vale do Rio Pardo.

As entidades parceiras ficaram responsáveis pela aplicação de um formulário para a localização de processos, produtos, máquinas e equipamentos desenvolvidos pelos agricultores familiares, durante suas atividades cotidianas nos municípios da região. Estes formulários foram aplicados entre 2017 e 2018. Posteriormente, a equipe de pesquisa do projeto se encarregou de tabular e sistematizar os dados coletados. A partir do método utilizado foram encontradas 58 técnicas, tecnologias, processos ou produtos gerados por agricultores familiares ${ }^{2}$. Tendo em vista este levantamento, foram identificados os casos considerados mais significativos pela equipe do projeto, com base no quadro teórico adotado e na indicação dos integrantes das organizações participantes, elegendo-se aqueles que primeiro receberiam uma vista para a aplicação de entrevistas semiestruturadas. A escolha acontecia da seguinte maneira: As equipes iam a campo com um formulário que foi elaborado pelos pesquisadores em parceria com as organizações parceiras (encontra-se em anexo); a partir dos resultados encontrados formulou-se uma tabela com todas as soluções localizadas, sua função, criador e localização; a equipe, composta por pesquisadores e parceiros das organizações discutiam quais tinham maiores possibilidades de modificar o trabalho dos agricultores que as utilizassem; a partir desta discussão eram feitas as visitas e entrevistas 3 .

Na sequência, foram realizadas um total de 18 entrevistas semiestruturadas com os agentes responsáveis pela criação novos processos, técnicas e equipamentos para a agricultura familiar, nos meses de novembro e dezembro de 2017 e fevereiro de 2018. Com a realização das entrevistas pretendeu-se apreender com mais detalhes e profundidade, os caminhos e processos que levaram a produção de determinada solução tecnológica e, portanto, a construção de determinado conhecimento, por parte dos agricultores familiares. As entrevistas foram gravadas e, na sequência

\footnotetext{
${ }^{2}$ Cabe ressaltar que a presente pesquisa não teve como objetivo realizar uma discussão acerca das relações de gênero no campo e/ou no processo de geração de soluções tecnológicas no contexto da agricultura familiar. Assim, apesar da relevância do tema, como o mesmo não fazia parte do escopo de pesquisa, não houve um direcionamento neste sentido, no processo de levantamento e localização realizado pelas entidades parceiras. Apesar do não direcionamento no processo de levantamento, percebeu-se a predominância dos homens na produção das soluções tecnológicas identificadas pelos diversos parceiros, a partir da aplicação dos formulários, em especial, quando estas tratam-se de máquinas e instrumentos destinados a atividade produtiva. Sendo assim, a partir do levantamento de campo pode-se inferir que:1) há uma divisão social do trabalho na agricultura familiar, em que os homens predominantemente assumem a tarefa de lidar com todos os processos relacionados às máquinas e equipamentos; 2) apesar de no processo de construção coletiva dos formulários, a equipe de pesquisadores do projeto ter enfatizado que soluções tecnológicas tratam-se de qualquer novas técnicas, tecnologias ou processos que, ao serem desenvolvidos e inseridos na atividade produtiva, modificam a maneira segundo a qual os agricultores trabalham, pode ser que a equipe não conseguiu enxergar as soluções geradas pelas mulheres; 3) Uma outra possibilidade é que devido justamente a divisão social do trabalho realizado no campo a equipe não conseguiu acessar as mulheres. Cabe destacar que quando explicava-se o tema da pesquisa e o que se buscava, os componentes da família entrevistada, inclusive as mulheres, já direcionavam a equipe de pesquisa para as atividades e soluções desenvolvidas pelos homens. Assim, discutir os desdobramentos de tais questões na identificação e produção de soluções tecnológicas, pode ser tema de pesquisas e reflexões futuras. 3 Uma descrição detalhada do método utilizado na pesquisa é encontrada em Mengel e Aquino (2018).
} 
transcritas, sistematizadas e analisadas. Também foram produzidas fotografias do material encontrado, cujo objetivo é compor o acervo documental de pesquisa ${ }^{4}$.

Dentre as questões abordadas pelas entrevistas para este trabalho foram privilegiadas informações colhidas a respeito dos seguintes temas: 1) O que foi criado? 2) Qual sua função? 3) Existe algo similar no mercado ou processo parecido?; 4) Caso exista, qual a razão de ter sido criado? (por exemplo, se o preço do produto existente é impeditivo, se a escala é inadequada, ou se o processo é mais eficiente; 5) Como ocorreu o processo de criação?; 5) Quais as transformações que tal solução criada produziu no cotidiano da família? Dado o espaço disponível para análise bem como em razão da amplitude do material coletado, o presente trabalho utilizará o conteúdo de 5 destas entrevistas.

\section{Resultados e Discussão}

Para a análise realizada neste artigo, dada a amplitude do material coletado e considerando o espaço disponível para análise, foram escolhidas cinco das 18 entrevistas realizadas, consistindo em casos representativos quanto às atividades desenvolvidas pelos agentes que criam as soluções tecnológicas, idade e posição geográfica na região analisada. Dos entrevistados foram selecionados os seguintes (Quadro 1):

Quadro 1- Casos analisados

\begin{tabular}{|c|c|c|l|}
\hline Agricultor & Idade & $\begin{array}{c}\text { Local de } \\
\text { Residência }\end{array}$ & \multicolumn{1}{|c|}{ Características profissionais } \\
\hline $\begin{array}{c}\text { Orlando } \\
\text { Konrath } \\
\text { (O. K.) }\end{array}$ & 47 & Vale do Sol & $\begin{array}{l}\text { Considera-se também como agricultor, mas, } \\
\text { atualmente, tem como atividade central a metalurgia. } \\
\text { Produz equipamentos específicos para a agricultura } \\
\text { familiar. }\end{array}$ \\
\hline $\begin{array}{c}\text { Domingos } \\
\text { Menegassi } \\
\text { (D. M) }\end{array}$ & 67 & Ibarama & $\begin{array}{l}\text { Define-se como ferreiro, marceneiro e agricultor, } \\
\text { sendo a atividade principal o trabalho em sua oficina. }\end{array}$ \\
\hline $\begin{array}{c}\text { Jean Sachet } \\
\text { (J. S.) }\end{array}$ & 33 & Ibarama & $\begin{array}{l}\text { Considera-se agricultor e produz tabaco, milho, mel e } \\
\text { outros alimentos para o autoconsumo. }\end{array}$ \\
\hline $\begin{array}{c}\text { Irineu Dors } \\
\text { (I. D.) }\end{array}$ & 58 & Sobradinho & $\begin{array}{l}\text { É aposentado, foi vidraceiro durante toda sua } \\
\text { trajetória profissional mas nunca deixou de ter relação } \\
\text { com a agricultura. Atualmente tem uma chácara onde } \\
\text { desempenha suas atividades produtivas e de } \\
\text { experimentação. }\end{array}$ \\
\hline $\begin{array}{c}\text { Helio Koff } \\
\text { (H. K) }\end{array}$ & 44 & Sinimbu & $\begin{array}{l}\text { Define-se como agricultor e durante toda a sua vida } \\
\text { desenvolveu suas atividades na mesma propriedade. }\end{array}$ \\
\hline
\end{tabular}

Na sequência, foram selecionadas algumas das soluções tecnológicas geradas pelos agricultores (expostas no Quadro 2). Estas evidenciam a existência de um processo de desenvolvimento de tecnologias por parte de agentes envolvidos diretamente com a agricultura familiar e para a agricultura familiar, sejam agricultores, ferreiros, marceneiros e/ou metalúrgicos. Posteriormente, será

\footnotetext{
4 As soluções tecnológicas encontradas estão sistematizadas no site 
detalhado que tipo de relação se estabelece entre os agentes locais que favorecem a geração dessas soluções 5 .

\section{Quadro 2 - Soluções tecnológicas geradas por agricultor, problema anterior existente anterior, benefício gerado pela solução e existência de solução semelhante no mercado}

\begin{tabular}{|c|c|c|c|c|c|}
\hline \multirow{2}{*}{ Criador } & \multicolumn{5}{|r|}{ (continua) } \\
\hline & $\begin{array}{l}\text { Atividade } \\
\text { produtiva }\end{array}$ & $\begin{array}{l}\text { Problema } \\
\text { existente }\end{array}$ & Solução gerada & Benefício Gerado & $\begin{array}{c}\text { Solução } \\
\text { semelhante } \\
\text { no mercado }\end{array}$ \\
\hline J.S. & $\begin{array}{c}\text { Cultivo de } \\
\text { tabaco/milh } \\
\text { o. }\end{array}$ & $\begin{array}{c}\text { Impossibilidade de } \\
\text { acamar a } \\
\text { cobertura verde } \\
\text { sem desmanchar } \\
\text { camaleões } \\
\text { necessários à } \\
\text { produção de } \\
\text { tabaco. }\end{array}$ & $\begin{array}{l}\text { Acamador com } \\
\text { pneus para } \\
\text { tração } \\
\text { mecânica }\end{array}$ & $\begin{array}{l}\text { Maior proteção } \\
\text { do solo pela } \\
\text { possibilidade de } \\
\text { realização de } \\
\text { semeadura direta }\end{array}$ & Não \\
\hline H. K. & $\begin{array}{l}\text { Produção } \\
\text { de melado e } \\
\text { geléias }\end{array}$ & $\begin{array}{l}\text { Dificuldade no } \\
\text { processo de } \\
\text { fabrico do melado, } \\
\text { o que exige muitas } \\
\text { horas de trabalho } \\
\text { de duas pessoas } \\
\text { para o produto } \\
\text { atingir a } \\
\text { consistência } \\
\text { exigida pelo } \\
\text { consumidor. }\end{array}$ & $\begin{array}{c}\text { Batedor de } \\
\text { melado elétrico }\end{array}$ & $\begin{array}{c}\text { Diminuição da } \\
\text { penosidade do } \\
\text { trabalho e } \\
\text { aumento de } \\
\text { produtividade. O } \\
\text { processo passa a } \\
\text { ocorrer em uma } \\
\text { hora, sendo } \\
\text { desempenhado } \\
\text { por uma pessoa. }\end{array}$ & Sim \\
\hline H. K. & $\begin{array}{l}\text { Produção } \\
\text { de grãos }\end{array}$ & $\begin{array}{c}\text { Infestação de } \\
\text { roedores e insetos. }\end{array}$ & $\begin{array}{c}\text { Galpão com } \\
\text { sistema de } \\
\text { expurgo } \\
\text { integrado. }\end{array}$ & $\begin{array}{c}\text { Completo } \\
\text { controle de } \\
\text { insetos e } \\
\text { roedores. }\end{array}$ & Sim \\
\hline J.S. & $\begin{array}{l}\text { Produção } \\
\text { de Suínos }\end{array}$ & $\begin{array}{l}\text { Mão de obra } \\
\text { necessária na } \\
\text { produção de } \\
\text { suínos. }\end{array}$ & $\begin{array}{l}\text { Tratador } \\
\text { automático. }\end{array}$ & $\begin{array}{l}\text { Maior eficiência } \\
\text { na utilização da } \\
\text { mão de obra, é } \\
\text { possível tratar o } \\
\text { animal com milho } \\
\text { a cada } 10 \text { dias. }\end{array}$ & Sim \\
\hline I. D. & Piscicultura & $\begin{array}{c}\text { Baixo teor de } \\
\text { nitrogênio na } \\
\text { água, } \\
\text { impossibilitando o } \\
\text { desenvolvimento } \\
\text { de fito plâncton. }\end{array}$ & $\begin{array}{c}\text { Mecanismo } \\
\text { para colocação } \\
\text { de humos de } \\
\text { minhoca na } \\
\text { água. }\end{array}$ & $\begin{array}{l}\text { Maior qualidade } \\
\text { da água com } \\
\text { menor custo de } \\
\text { produção. }\end{array}$ & Não \\
\hline
\end{tabular}

5 Tendo em vista as orientações da RESOLUÇÃO N 510, DE 07 DE ABRIL DE 2016, do Conselho Nacional de Saúde, no momento de realização das entrevistas o consentimento dos entrevistados que participaram da pesquisa foi coletado e gravado. 


\begin{tabular}{|c|c|c|c|c|c|}
\hline Criador & $\begin{array}{l}\text { Atividade } \\
\text { produtiva }\end{array}$ & $\begin{array}{l}\text { Problema } \\
\text { existente }\end{array}$ & Solução gerada & Benefício Gerado & $\begin{array}{c}\text { Solução } \\
\text { semelhante } \\
\text { no mercado }\end{array}$ \\
\hline I. D. & Piscicultura & $\begin{array}{l}\text { Necessidade de } \\
\text { ração com alto } \\
\text { teor de proteína }\end{array}$ & $\begin{array}{l}\text { Mecanismo } \\
\text { para alimentar } \\
\text { peixes com } \\
\text { minhocas. }\end{array}$ & $\begin{array}{l}\text { Alimento com } \\
\text { alta qualidade } \\
\text { produzido na } \\
\text { própria unidade } \\
\text { produtiva com } \\
\text { baixíssimo custo. }\end{array}$ & Não \\
\hline O. K. & $\begin{array}{l}\text { Cultivo de } \\
\text { batatas }\end{array}$ & $\begin{array}{l}\text { Arranquio manual } \\
\text { com baixa } \\
\text { produtividade do } \\
\text { trabalho e alta } \\
\text { penosidade. }\end{array}$ & $\begin{array}{l}\text { Arrancador de } \\
\text { batata } \\
\text { mecânico para } \\
\text { trator }\end{array}$ & $\begin{array}{l}\text { Arranquio com } \\
\text { rapidez e sem } \\
\text { penosidade. }\end{array}$ & Sim \\
\hline O. K. & $\begin{array}{l}\text { Várias } \\
\text { atividades } \\
\text { produtivas }\end{array}$ & $\begin{array}{c}\text { Alta penosidade e } \\
\text { baixa } \\
\text { produtividade do } \\
\text { trabalho para } \\
\text { rachar lenha }\end{array}$ & $\begin{array}{l}\text { Rachador de } \\
\text { Lenha } \\
\text { hidráulico para } \\
\text { trator. }\end{array}$ & $\begin{array}{c}\text { Alta } \\
\text { produtividade e } \\
\text { baixa penosidade } \\
\text { no processo de } \\
\text { rachar lenha. }\end{array}$ & Não \\
\hline D. M. & $\begin{array}{l}\text { Cultivo de } \\
\text { Tabaco }\end{array}$ & $\begin{array}{c}\text { Tecnologias de } \\
\text { prensagem } \\
\text { inadequadas }\end{array}$ & $\begin{array}{c}\text { Prensa com } \\
\text { rosca } \\
\text { (desenvolvido } \\
\text { há cerca de } 50 \\
\text { anos atrás) }\end{array}$ & $\begin{array}{l}\text { Melhor qualidade } \\
\text { na prensagem. }\end{array}$ & Não \\
\hline D. M. & $\begin{array}{l}\text { Fabricação } \\
\text { de torresmo }\end{array}$ & $\begin{array}{l}\text { Prensa de madeira } \\
\text { com maior } \\
\text { facilidade de } \\
\text { estragar e com } \\
\text { porosidade. }\end{array}$ & $\begin{array}{c}\text { Prensa toda de } \\
\text { metal } \\
\text { (desenvolvido } \\
\text { há cerca de } 50 \\
\text { anos atrás) }\end{array}$ & $\begin{array}{c}\text { Melhor qualidade } \\
\text { no produto final } \\
\text { e maior } \\
\text { durabilidade da } \\
\text { prensa. }\end{array}$ & Não. \\
\hline
\end{tabular}

O processo de geração de uma solução tecnológica na agricultura segue as próprias características dessa atividade produtiva. Tecnologia, como definido por Pinto (2005), é a reflexão sobre a técnica dominada, materializada em um instrumento, método, produto. A reflexão sobre a técnica, na agricultura, depende dos ciclos biológicos, assim, interage diretamente com a vida, pois o novo instrumento ou método deve se adequar às diferentes características de plantas ou animais ao qual se destina.

No caso da agricultura familiar, um dos elementos a se considerar é a característica do trabalho realizado pelo indivíduo que, ao mesmo tempo em que coordena as atividades, também desempenha todas elas. Portanto, este detém o conhecimento técnico detalhado de cada processo e sabendo do que necessita ser modificado para a obtenção do objetivo existente. Ademais, a reflexão sobre a técnica nesta categoria deve considerar, ainda, um ambiente de mercado extremamente competitivo e uma necessidade de criação de alternativas produtivas que diminuam custos, visto que esta categoria não tem condições de acessar as tecnologias geradas pela indústria. Ou ainda, pelo fato da indústria nem tentar gerar tecnologias para esta categoria, dada sua baixa capacidade de investimento. 
Ao ser questionado sobre como desenvolveu um acamador de aveia, utilizado como tecnologia de preparo de solo para o cultivo de tabaco, adequada a preservação do mesmo, o interlocutor J. S. explica que a partir da dificuldade de plantar e colher pensou que necessitava criar algo novo que fosse compatível com o uso do trator:

J.S. : Eu vou ter que inventar alguma coisa pra deitar, muitos pneus, fazer uma grade de pneus, isso pra boi é uma coisa, uma gradezinha de boi, tranquilo. E para trator como é que eu vou fazer? Aí experimentei em fazer ela em $V$, normal da grade boi em $V$, em $V$ ela não trabalhou. Aí eu fiz ela retangular.

Pesquisador: E quanto tempo você demorou pra bolar desse jeito?

J. S.: Até acertar, olha uns três dias lidando com ela.

Pesquisador: Em uma safra só?

J. S.: Sim! Ano passado eu fiz ela no fim da safra, pra acamar a aveia seca já, a aveia que eu tinha dessecado e ela não venceu acamar, e estava na hora de plantar, ai experimentei, ela acamou bem, só que ela arrancou muita aveia, ela estava morta, ai surgiu a ideia de acamar verde, verde ela não vai arrancar tanto, não vai limpar o solo, ai foi o que eu fiz esse ano, acamei verde. Bah, 100\%, bem melhor.

O tempo para a geração e teste da solução precisou ser compatibilizado com o ciclo agrícola, tendo em vista que a resolução só estava sendo demandada em períodos específicos, quando havia aveia para acamar. Além disso, observa-se que o desenvolvimento da solução depende de um conhecimento do comportamento da planta nas várias fases de cultivo, como ela se comporta com o novo instrumento quando está ainda verde, quando já está seco, após a fase reprodutiva. Esta reflexão sobre a técnica a ser desenvolvida e as características necessárias ao novo instrumento fazem parte do processo de geração da nova tecnologia. Observa-se ainda, que uma tecnologia parecida com esta criada pelo interlocutor não existe no mercado, mesmo sendo extremamente eficiente, que quando utilizada diminui o custo de produção e permite o preparo do solo de maneira a conservar suas características edáficas.

Outro exemplo de solução tecnológica criada pelo interlocutor J. S. é um comedor automático para suínos, bastante simples, construído todo em madeira, mas bastante eficiente, exigindo a reposição de ração ou milho somente a cada dez dias, o que diminui em muito a mão-de-obra na atividade.

Pesquisador: Você costuma fazer, criar coisas que você precisa pra propriedade?

J.S.: Sim.

Pesquisador: O que que você lembraria?

J.S.: Comedor para porco lá embaixo, comedor automático sabe.

Pesquisador: Comedor automático?

J.S.: Comedor automático, não comprei, fiz.

Pesquisador: Como que é esse comedor automático?

J.S.: Caixa de madeira, tu larga um saco concentrado, o porco vai comer lá em baixo, conforme vai comendo, vai caindo por conta.

Pesquisador: E tem pra comprar um parecido?

J.S.: Tem, comercial tem.

Pesquisador: Por que você fez e não comprou novo?

J.S.: Porque é mais fácil fazer do que de pagar.

Pesquisador: E para fazer você gastou muito?

J.S.: Só mão de obra. 
A fala do interlocutor evidencia a necessidade do agricultor familiar criar soluções próprias para sua atividade produtiva. Mesmo existindo tecnologias disponíveis no mercado, estas são muito caras para a realidade existente, o que exige a geração de soluções próprias. Tal posição no mercado torna a criação de soluções tecnológicas uma exigência para a manutenção do agricultor familiar como categoria social.

Ao ser questionado sobre a razão de gerar soluções próprias para suas atividades produtivas, em entrevista realizada em dezembro de 2017, o interlocutor H. K. explica "que isso é coisa de colono, tem que fazer". O interlocutor nos ajuda a compreender que criar é uma característica desta categoria social, ao mesmo tempo que é um ato de resistência, ou seja, é uma estratégia encontrada pela categoria para sobreviver em um mercado bastante competitivo.

Ao refletir sobre como ocorre a geração das soluções encontradas e sobre quem participa de sua criação, percebe-se a recorrência de alguns agentes. Os ferreiros, marceneiros, metalúrgicos, parceiros dos agricultores na geração de novas tecnologias, estão presentes nas comunidades locais e fazem parte de seu círculo de relações. Ao explicar como criou o batedor de melado, H. K. evidencia a importância de sua parceria com o ferreiro local.

H. K.: Tem um ferreiro ali embaixo, aí como a gente pede ele faz, aí eu expliquei pra ele que eu vi lá com roda de bicicleta, daí eu queria fazer uma engrenagem, então ele fez o cavalinho com madeira [...].

Pesquisador: Mas, as peças foi o senhor que pensou?

H. K.: Sim, a roda de bicicleta, as colheres, eu expliquei pro ferreiro.

Pesquisador: $O$ projeto é seu?

H. K: Sim, eu expliquei pra ele como era pra fazer. (Entrevista com H. K., dezembro de 2017).

Os agricultores não têm todos os equipamentos necessários para a elaboração de um projeto, embora, sejam eles que conheçam e tenham estudado a técnica a ser reproduzida pelo novo equipamento, ou seja, a tecnologia por ele incorporada. Os ferreiros/marceneiros ou metalúrgicos, assim, desempenham uma função importante no processo de reprodução da agricultura familiar. Estes agentes, muitas vezes, são agricultores também, ou são especialistas nestas tarefas na comunidade.

Ao entrevistar o senhor O. K., metalúrgico de Vale do Sol, é evidente a profunda relação que o mesmo tem com a agricultura familiar. Além de ter sido agricultor e de desempenhar algumas tarefas como agricultor até a atualidade, 0 mesmo atribui seu saber fazer à proximidade que mantém com os agricultores.

O. K.: Ah, eu acredito que tenho muita vantagem na linha agrícola porque fui agricultor e ainda hoje lido um pouco na agricultura. Então a gente tem que ter visão, eu analiso muito como os agricultores trabalham quando eu faço entrega no campo, fico analisando muito conforme eles trabalham, então ali tu tá vendo a necessidade de que eles precisam de melhoramento no equipamento. E que outras empresas grandes, de repente, botam uma engenharia lá dentro, fazem cálculo, tudo no papel, mas na prática de repente faltaria pra eles (Entrevista O. K., maio de 2018). 
O. K. salienta a importância da proximidade estabelecida entre ele e os agricultores, seus vizinhos. A partir desta proximidade, os agricultores o procuram quando têm ideias de equipamentos ou máquinas ou quando sabem que existem equipamentos no mercado, mas que estes precisam ser adaptados à realidade da agricultura familiar. Em ambos os casos, procuram o interlocutor porque sabem que este tem experiência na criação de soluções, porque este tem todas as ferramentas necessárias para a criação do novo equipamento, bem como, que este escuta e desenvolve as soluções sugeridas. Ao descrever esta relação, O.K. fortalece a percepção de que há um arranjo de atores locais envolvidos em um processo de geração de conhecimento, materializado em novas ou diferenciadas tecnologias para a agricultura familiar.

Pesquisador: É comum o senhor fazer adaptações para implementos agrícolas?

O. K.: É, eles veem os produtos, aí eles têm uma ideia e querem algo diferenciado.

Pesquisador: E eles the procuram?

O. K.: É, isso eles não vão achar no mercado pronto, precisa da adaptação. Se não tem empresa que vai fabricar em série, e um cliente vai querer assim, outro assim, então, essas questões eles vêm me procurar. (Entrevista O. K., maio de 2018).

Percebe-se por um lado, que esses conhecimentos gerados, bem como os instrumentos fabricados a partir de necessidades concretas dos agricultores, já trazem embutidos a relação entre teoria e prática. Por outro lado, é possível constatar também que a criação destes instrumentos e a produção dos conhecimentos aqui assinalados só são possíveis a partir da relação que esses distintos agentes estabelecem entre eles, numa junção de conhecimentos, de práticas e também de teorias. Ademais, tendo em vista o relatado processo de adaptação de equipamentos para o contexto da agricultura familiar, percebe-se também que "tão importante quanto a capacidade de produzir novo conhecimento é a capacidade de processar e recriar conhecimento, por meio de processos de aprendizado" (ALBAGLI e MACIEL, 2004, p.10).

D. M., um ferreiro/marceneiro e agricultor do município de Ibarama, descreve como sua relação de proximidade com os demais agricultores foi importante para criar a prensa de fumo com rosca, bastante utilizada na região por muitas décadas.

Pesquisador: $\mathrm{O}$ senhor adaptou uma prensa que veio ou o senhor fez uma prensa nova?

D. M.: Não, eu vi lá como eles [agricultores] reclamaram, e inventei uma nova de madeira, um jeito novo. Primeiro era aquelas com pau, aquela bagunça. Ai eu troquei, comecei a botar com trava, buscava as travas, que aqui não faziam e colocava na prensa né. Hoje está mudando tudo, já com catraca, nós quem fabricamos também (Entrevista com D. M., fevereiro de 2018).

Já ao descrever o processo de criação da prensa de torresmo sem madeira, toda em metal, ocorrido há cerca de 50 anos atrás, D. M., fala de sua parceria com o metalúrgico do município. Ele conhecia a técnica de fabrico de torresmo perfeitamente, conhecia os problemas da prensa de madeira e sabia da possibilidade 
de criar uma prensa de metal. Entretanto, não tinha os equipamentos e materiais necessários.

Pesquisador: Aquela prensa de torresmo de metal não tinha no mercado antes?

D. M.: Não! Quem começou foi eu, junto com o falecido pai. Aí eu disse pro falecido meu pai, "pai eu vou inventar uma prensa moderna, vamos fazer, vamos tentar". Ele me disse, "ah vai botar fora dinheiro, não eu vou botar não". Aí fui lá [no metalúrgico], tomei um dia só, com aqueles tonel, que tinha funilaria né, para fazer.

Pesquisador: Então você comprava o tonel dele [metalúrgico] e vinha fazer o resto aqui?

D. M.: Ele só cortava, soldava, e o resto eu fazia tudo.

Pesquisador: Vendeu bastante desta peça?

D. M.: Não tem ninguém quase que não tem essa prensa.

Pesquisador: Às vezes o senhor pensava alguma coisa, mas procurava um outro colega para ajudar?

Pesquisador: Eu dependia da folha [de metal] dele, eu não tinha o metal. (Entrevista com D. M., fevereiro de 2018).

A descrição do processo de criação da prensa de torresmo evidencia que um conhecimento para ser cristalizado em uma nova tecnologia precisa dos meios adequados para tal. Os agricultores poderiam saber dos problemas técnicos do processo de fabrico do torresmo com prensa de madeira, mas, o senhor D. M. só conseguiu solucionar o problema, criando uma nova tecnologia, por meio da relação que estabeleceu com o metalúrgico local que tinha os equipamentos e o saber-fazer para fabricar as peças necessárias à nova prensa.

A partir da reflexão a respeito de como ocorre o processo de geração de soluções tecnológicas na agricultura familiar, percebe-se um tipo de arranjo local de conhecimento. Deste arranjo participam os atores já citados, agricultores, ferreiros/marceneiros e metalúrgicos. $\mathrm{O}$ arranjo pode ser expressado pela figura 1. 
Figura 1 - Relações estabelecidas na Agricultura Familiar para a geração de soluções tecnológicas próprias ${ }^{6}$

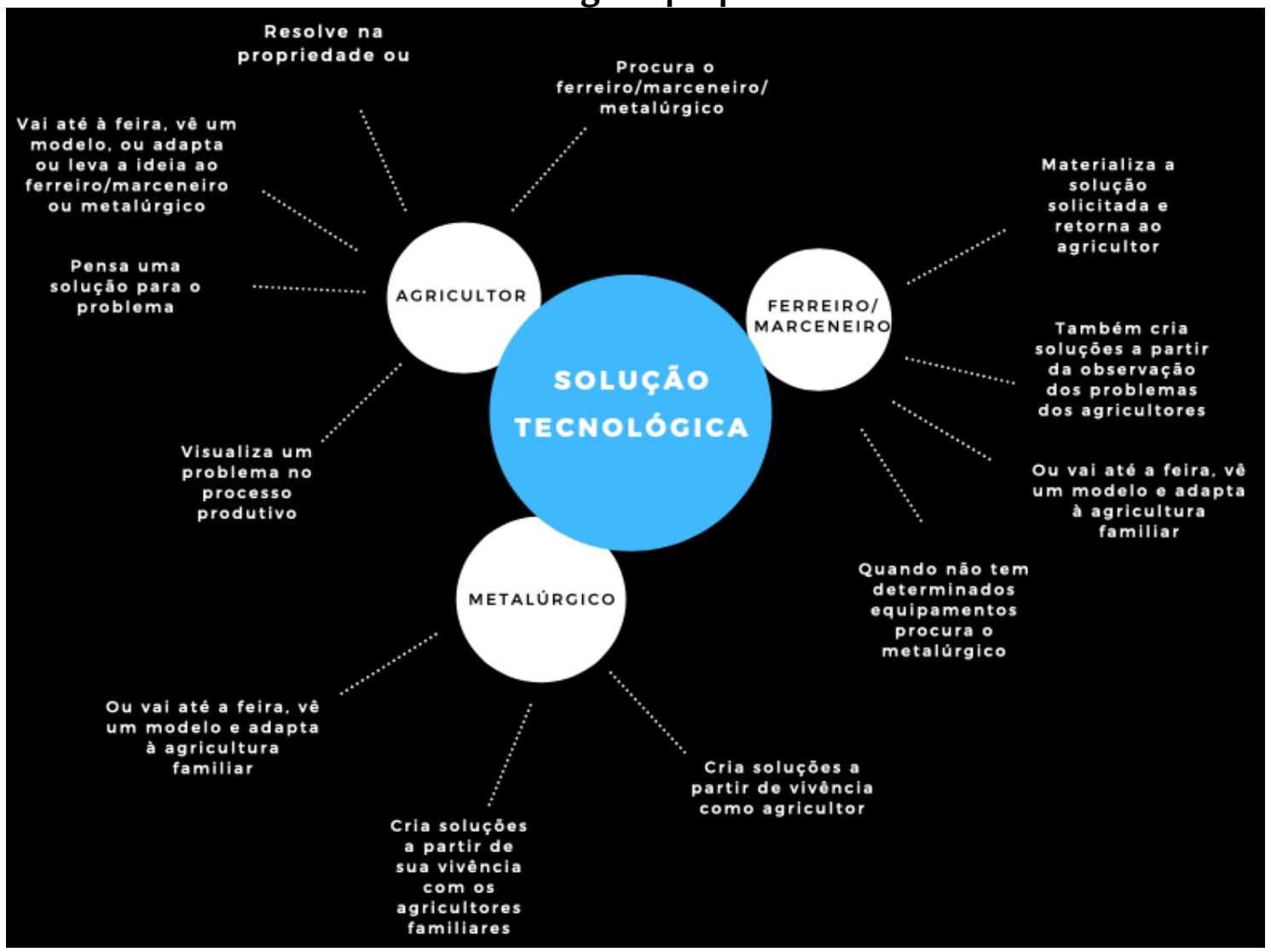

Fonte: Elaboração dos autores (2019)

A dinâmica de geração de soluções tecnológicas percebida a partir das entrevistas realizadas com os agricultores e demais atores sociais, como ferreiros e metalúrgicos é a seguinte: 1) o agricultor tem um problema, reflete sobre as formas de resolvê-lo, pensa a solução, por vezes consegue desenvolvê-la sozinho ou com seus vizinhos, sem equipamentos e materiais específicos; 2) quando não consegue, procura o ferreiro, que normalmente também é marceneiro, ou o metalúrgico presente em sua localidade, explica o problema e a possível forma de resolvê-lo, um possível equipamento; 3) o ferreiro ou metalúrgico desenvolve o novo instrumento, como o solicitado; 4) o agricultor experimenta e caso não estiver bom, retorna e explica os problemas encontrados e as possíveis soluções, se tiver o equipamento adequado, ele mesmo o faz; 5) depois de testado e aprovado, o agricultor dá o retorno positivo ao seu parceiro construtor e encerra-se um ciclo de geração de uma nova tecnologia agrícola. A partir deste momento, alguns agricultores da vizinhança passam a tomar conhecimento da nova maneira de fazer, as soluções tecnológicas são socializadas e avança-se no processo de geração de conhecimento em nível local.

${ }^{6} \mathrm{Na}$ figura 1, as feiras são colocadas no processo, porque todos os agricultores a citaram como um lugar de buscar novas ideias para adaptar na propriedade. O metalúrgico O. K., além de participar da principal feira da região, a Expoagro, desenvolve uma feira própria, evidenciando a importância que estes espaços têm para os agricultores. 
Neste contexto, um ponto importante a ser destacado é o de que os agricultores não procuram manter segredo a respeito do novo processo ou instrumento criado, ao contrário, para eles, saber que outros agricultores passaram a usar a ideia desenvolvida é motivo de orgulho e contentamento, o que fica visível nos relatos analisados anteriormente. Deste modo, percebe-se que "a produção, a socialização e o uso de conhecimentos e informações (...) constituem processos socioculturais e que tais práticas e relações inscrevem-se no espaço e na própria produção do espaço, em suas várias escalas" (ALBAGLI e MACIEL, 2004, p.9).

Ademais, com base em Long (2007) verifica-se que a agência não é simplesmente o resultado de algum tipo de dom extraordinário, uma capacidade mística, um toque empreendedor ou um manifestação do espírito inovativo adquirido por talentos individuais. A agência é gerada socialmente e é um fenômeno definido culturalmente, o que leva a diferentes formas de manifestação dependendo do contexto analisado. A noção de agência está incorporada nas relações sociais e só pode ser efetivada através dela.

\section{Conclusões}

A análise realizada permite afirmar que os agricultores familiares, além de produzirem alimentos, fibra e energia, geram novos conhecimentos, expressos em soluções tecnológicas próprias, desenvolvidas localmente. Tais soluções são importantes para a manutenção do próprio agricultor como categoria social.

A geração de soluções tecnológicas próprias é um elemento característico e definidor dos agricultores familiares como categoria, tendo em vista que estabelecem e têm clareza sobre os objetivos de sua atividade socioeconômica, ao mesmo tempo em que desenvolvem cada uma das tarefas existentes em sua unidade produtiva. Tal característica permite que o agricultor familiar identifique os problemas de cada processo e pense maneiras de solucioná-lo, seja modificando um método produtivo ou criando uma nova máquina ou equipamento.

Se o agricultor somente dirigisse o estabelecimento, não saberia o que modificar. Se só desempenhasse as atividades, não teria liberdade para fazer a mudança. O agricultor familiar combina ambas as características, por isso é capaz de gerar tecnologias próprias, eficientes, sejam simples ou não. O desafio, do ponto de vista acadêmico, é como passar a considerar relevantes estes arranjos locais de geração de conhecimento, ampliando-os, de modo que a Universidade se insira nesse processo, bem como, que utilize estas experiências na própria construção do conhecimento acadêmico.

\section{REFERÊNCIAS}

ABRAMOVAY, R. Paradigmas do capitalismo agrário em questão. São Paulo: Unicamp e Hucitec, 1998.

ALBAGLI, Sarita; MACIEL, Maria Lucia. Informação, conhecimento e Inovação no Desenvolvimento Local. Ciência da Informação (Online), v. 33, n.3, p. 09-16, 2004. 
BAIARDI, Amilcar; ALENCAR, Cristina Maria Macêdo de. Agricultura familiar, seu interesse acadêmico, sua lógica constitutiva e sua resiliência no Brasil. Rev. Econ. Sociol. Rural, Brasília, v. 52, supl. 1, p. 45-62, 2014 . Disponível em: <http://www.scielo.br/scielo.php?script=sci_arttext\&pid=S010320032014000600003 \&lng=en\&nrm=iso >. Acessado em 14 abril de 2018.

FEIX, Rodrigo Daniel; LEUSIN JÚNIOR, Sérgio. Painel do agronegócio no Rio Grande do Sul - 2015. Porto Alegre: FEE, 2015.

GOODMAN, David; SORJ, Bernardo; WILKINSON, John. Das Lavouras às Biotecnologias: agricultura e indústria no sistema internacional. Centro Edelstein de Pesquisas Sociais, Rio de Janeiro, 2008.

GIDDENS, A. A constituição da sociedade. 3. ed. São Paulo: WMF Martins Fontes, 2009.

. The constitution of society: an outline of the theory of structuration. UK: Cambridge, Polity Press, 1984.

JEAN, B. A forma social da agricultura familiar contemporânea: sobrevivência ou criação da economia moderna. Cadernos de Sociologia, PPGS/UFRGS, Porto Alegre, v. 6, p. 76-89, 1994;

KARNOPP, Erica. Tendências de desenvolvimento da agricultura familiar: uma análise regional. RDE - Revista de Desenvolvimento Econômico, v. 14, p. 99-110, 2012.

LONG, Norman. Development sociology: actor perspectives. London: Routledge, 2001.

. Sociología del desarrollo: una perspectiva centrada en el ator. México:

Centro de Investigaciones y Estudios Superiores en Antropología Social, 2007.

MENEZES, Marilda; MALAGODI, Edgard Afonso . Os camponeses como atores sociais: a perspectiva da autonomia e da resistência. $24 \mathrm{p}$. Versão preliminar. Disponível em: <http://www.ufrgs.br/pgdr/arquivos/ipode_35.pdf >. Acesso em: jun. 2015.

PINTO, Álvaro Vieira. O conceito de tecnologia. Vol. 1. Rio de Janeiro, Contraponto, 2005.

SCHNEIDER, S. Teoria social, agricultura familiar e pluriatividade. Revista Brasileira de Ciências Sociais, São Paulo, V. 18, nº 51, p.99-123, 2003.

SCHUMPETER, Joseph Alois. Teoria do Desenvolvimento Econômico: uma investigação sobre lucros, capital, crédito, juro e o ciclo econômico. Tradução de Maria Sílvia Possas. Ed. Nova Cultural Ltda, São Paulo, 1997. 
SHANIN, Teodor. A definição de camponês: conceituações e desconceituações - o velho e o novo em uma discussão marxista. Revista Nera, Presidente Prudente, ano 8, n.7, 2005, p. 1-21.

WANDERLEY, Maria de Nazareth Baudel. Agricultura familiar e campesinato: rupturas e continuidade. In: Estudos sociedade e agricultura, Rio de Janeiro, v.1, n.2, p.42-61, out. 2003.

. O campesinato brasileiro: uma história de resistência. RESR, Piracicaba-SP, Vol. 52, Supl. 1, p. So25-S044, 2014 - Impressa em Fevereiro de 2015.

. Raízes históricas do campesinato brasileiro. In: TEDESCO, J. C. Agricultura familiar: realidades e perspectivas. Passo Fundo, Ed. UPF, 1999, (p.23-56).

WOLF, Eric. Las Luchas Campesinas del Siglo XX. Siglo Veintiuno Editores, México, 1972.

Alex Alexandre Mengel. Professor Adjunto na Universidade Federal do Rio Grande do Sul (UFRGS) - Campus Litoral Norte - Bacharelado Interdisciplinar em Ciência e Tecnologia. Doutor em Ciências Sociais pelo Programa de Pós-Graduação de Ciências Sociais em Desenvolvimento, Agricultura e Sociedade, da Universidade Federal Rural do Rio de Janeiro. alexandremengel@gmail.com

Silvia Lima de Aquino. Professora da Universidade Federal do Rio Grande do Sul (UFRGS) - Campus Litoral Norte, no Departamento Interdisciplinar. Doutora em Ciências Sociais pelo Programa de Pós-Graduação de Ciências Sociais em Desenvolvimento, Agricultura e Sociedade da Universidade Federal Rural do Rio de Janeiro.silvia.aquino@gmail.com

Cidonea Machado Deponti. Professora Adjunta na Universidade de Santa Cruz do Sul. Doutora em Desenvolvimento Rural pelo Programa de Pós-Graduação em Desenvolvimento Rural da Universidade Federal do Rio Grande do Sul. cidonea@unisc.br

Silvio Cezar Arend. Professor Adjunto na Universidade de Santa Cruz do Sul. Doutor em Economia pela Universidade Federal do Rio Grande do Sul. silvio@unisc.br

Como citar: MENGEL, Alex Alexandre et al. Agricultura Familiar e Soluções Tecnológicas agentes locais como protagonistas na geração de conhecimento. Redes (St. Cruz Sul, Online), Santa Cruz do Sul, v. 25, n. 1, jan. 2020. ISSN 1982-6745.

DOI: https://doi.org/10.17058/redes.v25i1.14679. 
Agricultura Familiar e Soluções Tecnológicas - agentes locais como protagonistas na geração de conhecimento

\section{CONTRIBUIÇÃO DE CADA AUTOR}

Fundamentação teórico-conceitual e problematização: Alex Alexandre Mengel, Silvia Lima de Aquino e Cidonea Machado Deponti

Pesquisa de dados e análise estatística: Alex Alexandre Mengel, Silvia Lima de Aquino, Cidonea Machado Deponti e Silvio Cezar Arend

Elaboração de figuras e tabelas: Alex Alexandre Mengel e Silvia Lima de Aquino

Fotos: Alex Alexandre Mengel

Elaboração e redação do texto: Alex Alexandre Mengel, Silvia Lima de Aquino e Cidonea Machado Deponti

Seleção das referências bibliográficas: Alex Alexandre Mengel, Silvia Lima de Aquino e Cidonea Machado Deponti 